\title{
Design science masterplan in improving online investing decision support services
}

\author{
Antti Paatela ${ }^{1}$ \\ ${ }^{1}$ Faculty of Business and Economics, University of Lausanne, CH-1015 Lausanne, Switzerland
}

\begin{abstract}
Online services supporting consumer investing have proliferated during the last three decades. Empirical research has discovered that overperforming investors started to underperform after switching to online investing services. Recent studies have revealed that individuals ignore the decision support provided by incumbent investing platforms, relying on their instincts instead. In response, a research project was launched, with the main goal to define technology, acceptance and service ecosystem originated reasons for not meeting investor expectations. A 'design science master plan' process was developed to identify and filter critical developments from a large number of suggested improvements. The ultimate goal was to enable a self-directed investor to manage investing assets with a performance of a professional, but with better control than delegated or fully automated investing services allow. A sample of live online investing platforms was used for problem discovery. In remote-controlled experiments, ten investors representing five investor personas evaluated the selected services. Identified problems and opportunities were analysed and conceptualised, after which design evaluations were made. Participants prioritised the defined development initiatives in terms of relevance and expected personal acceptance. A suggestion for more modular and specialised service architecture was made.
\end{abstract}

Keywords:

Design science research, online investing services, service modularisation, decision support systems, retail investor

\footnotetext{
${ }^{1}$ Corresponding author: antti.paatela@gmail.com
} 


\section{Introduction and empirical research review}

The performance of online investing service users has been studied primarily in two empirical waves: in 1999-2010 [1-7] coinciding with a strong growth in online investing and later in 2020-2021, after zero-commission investing services and 'smartphone investing' had emerged [8-12]. Depending on the source, a yearly investor underperformance of $1.5 \%-8 \%$ has been detected, as well as occasional pockets of overperformance. Ibbotson et al. [13] found that portfolio asset allocation explains $90 \%$ of performance. Despite this prescriptive knowledge, investors do not fully diversify their portfolios [14]. Results of empirical research produce occasionally controversial results; studies may not acknowledge the heterogeneity of online users and limitations of quantitative data acquired from a single financial institution [15]. With relation to investing performance, Barber et al. [16] made a puzzling finding that previously overperforming investors who switched from telephone-based execution to online investing services started to underperform 3\% annually. The question as to whether this outcome occurred as a result of using services online or from no longer having access to a human broker, remains unanswered. Reported reasons for switching to self-directed online investing include reduction in commissions, ease of execution, need for control and overconfidence.

The above-mentioned empirical studies were based on quantitative analysis of transaction or investing account data. A qualitative study [17] with a sample of 32 investors in three countries found that investors' use of platform decision support functionality was limited. In their comments, investors indirectly addressed a mismatch between their needs and offered services: "I use maybe 1-2\% of the features"; "95\% of the time I do only 2 or 3 things there" and "I only use the platform for executing the decisions I have already made". As further evidence of a service gap, investors were using multiple online platforms in parallel. They had developed their own spreadsheets to support decision-making.

The starting point of this study was to explore whether the identified service mismatches derived from technology or user acceptance, and what were the implications of the service ecosystem for online investing. The study addressed these questions first by analysing and experimenting with incumbent online platforms to discover shortcomings and opportunities. Thereafter, a multistage design science master plan process (Figure 2.1) was applied to arrive at a holistic apprehension of development priorities. Investing platform services were evaluated by a sample of 10 investors. Investor heterogeneity was addressed by theoretical sampling of users, grouped into five different investor personas.

Section 3 (Findings) presents the development initiatives and their evaluations. Of the problems type initiatives, portfolio performance feedback, reduction of unnecessary complexity and management of abundant information flows were key priorities. Regarding new solutions, investors demonstrated a high acceptance of holistic investor profiling, intelligent security selection and introduction of scenario-based simulations in portfolio building.

Section 4 (Discussion) puts forward the notion that the role of sociopsychological aspects complement utilitarian needs. Investors were discovered to be unexpectedly resilient to usability problems - investors were not to be blamed for poor acceptance of decision support functions. On the contrary, investors could be nudged to use advanced decision support tools in case such functions were perceived enjoyable. A suggestion to amplify value creation by bundling external services and streamlining in-house services is made. Modularisation of 
online investing services is proposed as a potential solution to remove a mismatch between investor needs and services provided.

Section 5 concludes the findings and proposes the service life-cycle concept as a partial explanation for the current service gaps. Responding to diverging customer segments and their needs is seen as a generic solution to improve business models. Achieving an effective service ecosystem modularisation may require an introduction of further financial policy measures beyond current open banking policy initiatives.

\section{Design science master plan methodology}

\section{Overall research design}

Focusing on decision support services provided by online investing platforms, the key data sources were samples of live platforms and investors. This study had access to online investing accounts and investor contacts of an ongoing larger research project. The corresponding data were collected in 2019-2021.

The online investing platform sample included eight platforms from USA, Switzerland and Nordic countries. The criteria for platform selection consisted of a profile of a generalpurpose investing platform, broad recognition among investors and availability for international account holders. To be considered a platform, the service provider was required to offer asset custody, transactions, reporting, and portfolio analyses as a minimum. Platforms were used for identifying generic and collective shortcomings - not for comparison.

The investor sample included 10 investors from Switzerland, Finland, and the USA. Requirements for investors were minimum of five years of investing experience, a minimum of 50'000 euros investing portfolio and pursuing of self-directed portfolio management. The selection criteria were essential to avoid studying mostly experimenting investors of whom $75 \%$ may quit in two years [8]. Diversity in investor practices has also been found to decrease with years of experience due to the effect of investing experience cycle [17].

Investors only using automatic investing accounts were excluded, as they were not considered self-directed investors. For meaningful investor feedback analysis, the investors were divided into 5 investor personas:

1) Passive diversifier - an investor focusing on reaching a diversified portfolio; few transactions per year

2) Buy\&hold stock-picker - stock selection is considered key for investing performance

3) Engaged stock-picker - as the previous persona, but spending considerable time in analysing new investments and revisioning a portfolio in case of company outlook changed

4) Active-passive investor - the most active investor persona making occasional opportunistic transactions; nevertheless, maintains also a passive sub-account for long-term investments

5) Traditionalist - executes a proportion of orders by contacting a broker, possibly exchanging perceptions upon the investing environment 
An explorative research design was selected due to the research problem with initially unknown boundaries. The qualitative research methods included:

- Technical analysis of online platforms; selection of user demonstration functionality

- Participative semi-structured interviews with user remote-controlled platform experimentation

- Two rounds of semi-structured evaluation interviews with the investor sample

The overarching research paradigm was design science - the pragmatic design camp [1820]. Although pragmatic, the application of a new type of design science process is a contribution to the design science theory camp [21-24]. The study started from problem discovery and ended in artifacts. Artifact forms include designed constructs, models, methods, system instantiations and social innovations [18]. In this ex-ante focused study, artifacts range from problem definition, solution requirement, and conceptual models, to solution concepts.

\section{The design science master plan (DSMP) process}

Due to the nature of the study - the user is an independent consumer instead of an organisation, the design research did not start from a specific known problem but from problem discovery leading to identification of multiple problems. In addition to problems, newly ideated functions - opportunities - were included, responding to ideas and suggestions made by stakeholders. The large number of heterogenous development initiatives called for additional steps in ex-ante evaluations compared to traditional design science approach. The master plan nature of the developed process included identifying and filtering key generic development initiatives before solution conceptualisations. The process ends with selection and definition of design science initiatives - proposals for future build-evaluate type design research. The design science research (DSR) process used in this study was based on the proposal of Sonnenberg and Brocker [25], added with extra steps for narrowing the development focus. The structure of the process is depicted in the Figure 2-1 below and explained thereafter. 


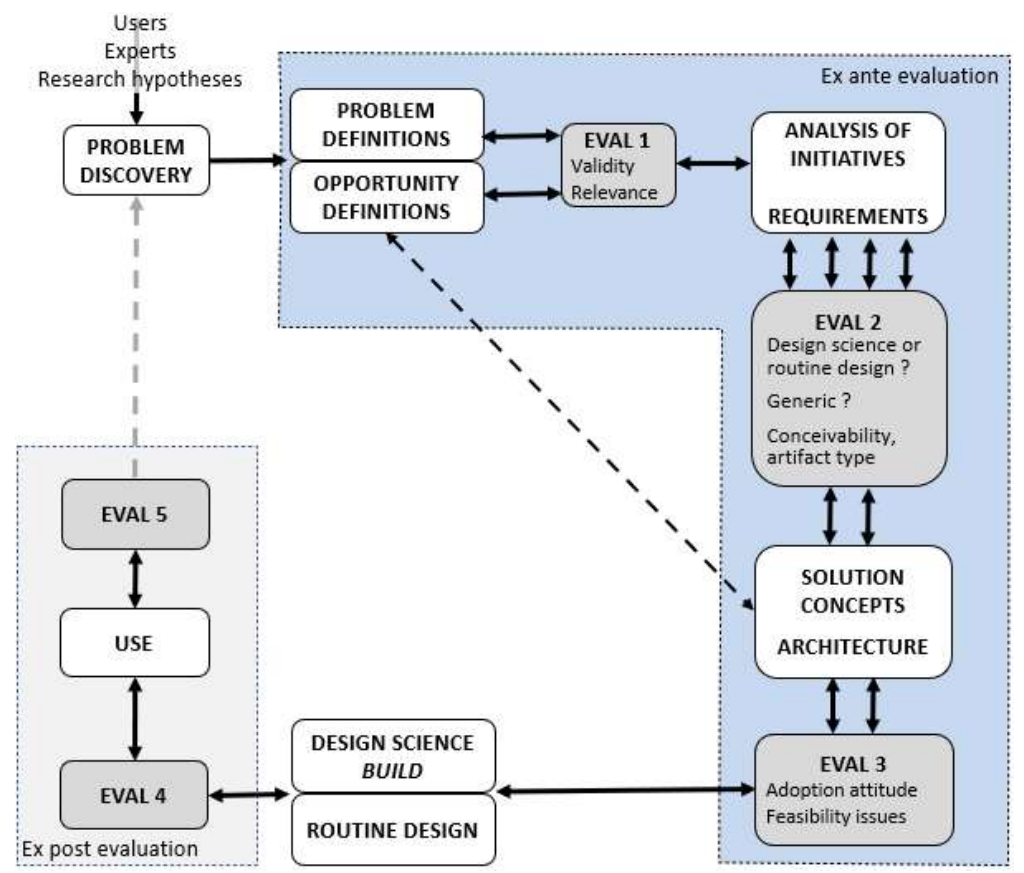

Figure 2-1. Stages of the design research process used. The goal was to arrive to the most impactful solution concepts from a large number of development initiatives. In EVAL1 and EVAL2, the least relevant initiatives were filtered out. The 'ex-ante evaluation' area on the right is included in this study and covers the concept 'Solution Incubation' by Holmström et al.[26]. The solutions to the simplest initiatives did not require the creation of a solution concept, but definition of objectives and target outcome.

The problem discovery started with a technical analysis of case platform functionality using an adapted investing process template [27] as a benchmark. Shortcomings and example functionality were gathered for a later review with investors. In participative interviews, selected functions across case platforms were analysed together with investors in experimental semi-structured interviews, where users had remote access to the platforms reviewed. A list of development initiatives was created based on perceived portfolio management problems and development ideas for improved support for investing related decision-making.

For relevance evaluation (EVAL 1), the problem-type development initiatives were analysed from a 'whole problem' perspective. Problems were broken down and ramifications identified. The evaluation resulted in the elimination of ideas perceived as not essential. The new solution initiatives considered relevant were further conceptualised for assessment of design needs. In EVAL 2, Initiatives were divided into routine design and design science based on the nature of a problem or new solution. Further work focused around design science initiatives. At this phase, new solutions were conceptualised to their final format for user 
acceptance evaluation. Regarding architectural issues recommended by Nunamaker [20], links between functions and possibilities for modularisation of decision support services were addressed.

The summative evaluation (EVAL 3) aimed to anticipate the success of potential future implementations. As all the suggested solutions were expected to improve investing performance, evaluation focus was on the user adoption of functionality - a weak point of incumbent platforms. The term adoption attitude was used to emphasize that users had no working prototype to test, but their perceptions of the usefulness of a solution was based on a presented solution concept. Adoption attitude was considered positive in case a user showed an intention to test an initiative for regular use were it to become available.

\section{Limitations and exclusions}

Automatic investing services like robo-advisors were excluded as these are not considered self-directed investing. Potential fees for services and data were ignored in platform analyses. The evaluations were done as subjective assessments by 10 investors. The results offer no statistical evidence. The study can be considered more as a multiple case study, where the defined five investor personas each form a case - providing explanations for different viewpoints of varying customer segments. Due to the investor sample requirement of experience in investing, the results are valid for investors having found a sustainable investing style. Perceptions of a sample of beginner, experimental and purely speculative users would likely be different.

\section{Findings - analysis of problems and opportunities}

The problem and opportunity discovery process described in Section 2 resulted in the initiative list in Table 3-1. The development needs are generic, but there is variation on how the issues manifest on platforms. Idiosyncratic platform problems were not addressed.

Table 3-1. Online platform improvement initiatives and their origins.

\begin{tabular}{|c|c|c|c|}
\hline $\begin{array}{l}\text { DEVELOPMENT INITIATIVES } \\
\text { Problem-solving, user-interaction and new solutions }\end{array}$ & \begin{tabular}{|l|} 
Platform \\
tech. \\
analysis \\
\end{tabular} & $\begin{array}{l}\text { Participative } \\
\text { interviews }\end{array}$ & $\begin{array}{l}\text { Practitioner } \\
\text { consultations }\end{array}$ \\
\hline \multicolumn{4}{|l|}{ 1. FUNCTIONAL PROBLEMS } \\
\hline Limited investing return feedback & $\mathbf{X}$ & $\mathbf{X}$ & $\mathbf{X}$ \\
\hline Limited portfolio level decision support & $\mathbf{X}$ & & $\mathbf{X}$ \\
\hline Information overflow, non-analytic decision support & & $\mathbf{X}$ & \\
\hline \multicolumn{4}{|l|}{ 2. DESIGN/INTERACTION ISSUES } \\
\hline Complexity, lack of intuitiveness and usability & $\mathbf{X}$ & $\mathbf{X}$ & \\
\hline Behavioural provocation instead of mitigation & & $\mathbf{X}$ & \\
\hline \multicolumn{4}{|l|}{ 3. NEW DECISION SUPPORT SOLUTIONS } \\
\hline Holistic investor profiling & $\mathbf{X}$ & & \\
\hline Hierarchical portfolio concept & $\mathbf{X}$ & & $\mathbf{X}$ \\
\hline Intelligent security selection & & $\mathbf{X}$ & \\
\hline Interactive portfolio revisioning & $\mathbf{X}$ & $\mathbf{X}$ & \\
\hline Automatic monitoring & $\mathbf{X}$ & & \\
\hline Investing process management & $\mathbf{X}$ & & $\mathbf{X}$ \\
\hline
\end{tabular}


In this short paper, the problem and opportunity definitions described thereafter are not presented in full detail. The main outcome of this paper is not the development initiatives themselves, but the investor persona reactions to initiatives, investor reasoning behind perceptions, and conclusions from an online investing services perspective.

\section{Functional problems and design/interaction issues}

\section{Limited investing return feedback}

'Limited' is considered to mean any lapse of information which may limit users' investing performance conception. The identified investing return related problems can be divided into the following classes of problems: access to return data was perceived troublesome; lack of clarity, which return components were included. Depending on the platform, access to historical data was limited; return data was erroneous or appeared confusing for an investor.

\section{Limited portfolio level decision support}

Portfolio level planning functionality, like portfolio allocation, creation, and revisioning tools were found in two of the eight platforms, but in participative interviews no investor considered them easy enough to use. Rebalancing utilities were absent.

\section{Information overflow and non-analytic decision support}

This problem manifested itself in investors complaining about too much data to analyse to arrive at a rational decision. Part of the displayed data on platforms was considered less important or seen even as "data noise". Interpretations or conclusions based on data were rare.

\section{Complexity, lack of intuitiveness and usability}

In the participative investor evaluations of platforms, investor requests for platforms to be "simpler" was a strong pattern. The exact same wording was used by several investors. Expressions leaning to a similar direction referred to "unnecessarily complex", "all kinds of bells and whistles", "their messy user interface" or "this... useless clutter" among others.

\section{Behavioural provocation instead of mitigation}

This is the unintentional or intentional impact of online platforms to trigger investor emotions resulting to hasty decision-making and an increase in transaction commissions. The negative impact of online platforms on decision-making has already been discovered by empirical literature [16] [28].

\section{New solution conceptualisations}

Note that the existence of a problem is not a precondition for new solution concepts. Initiatives may originate from abductive inference by investors, experts or researchers. 


\section{Holistic investor profiling}

The suggested holistic investor profiling is a support function for other solution initiatives. Due to regulatory requirements, risk profiling on investing platforms is already done to fulfil these obligations. The idea of holistic user profiling is to complete existing information on a platform with additional investor profile information, and to use that information to improve customer experience and to enable new decision support functions.

\section{Hierarchic portfolio concept}

Regarding portfolio analyses, investors voiced a need to consolidate multiple portfolios together for a global portfolio view. Sub-accounts were not requested by investors but were added to the concept as a suggested extension. In an ideal case, an investor could freely consolidate and break investments down into investor-defined groups for analysis purposes - not just by broker account.

\section{Intelligent security selection}

Security selection is a high-priority investing task for most investors interviewed in this study. It is seen as one of the key drivers for investing performance. Finding an investment may happen passively or actively. The suggested solution filters out themes expected to be irrelevant for an investor and pattern matches investments with the investor profile.

A passive type of security search was considered distracting if it took place in a form of unfocused and unfiltered push messages. Example quotes: 'I would like to follow systematically and not to receive all these random signals'; 'They should not send me stocks in markets I'm not invested. [...] why suddenly they ask me to have something exotic?'. Active searches were compared to "finding a needle from a haystack".

\section{Interactive portfolio revisioning}

In the interactive portfolio revision concept, the user builds a portfolio by iteratively changing the portfolio in a what-if manner. Portfolios revision are analysed with static measures or dynamic scenario data for multi-year performance simulations. When planned changes have been reached, the user can compare current and revised portfolio plans against each other and effectuate changes as a batch run. Portfolio scenario simulations can be done using public domain historical stock exchange data and licensed proprietary future scenario data.

\section{Automatic monitoring}

Incumbent platform monitoring is based on asset prices. Investors found setting up alerts time-consuming and receiving of alerts distracting. Using a service quality framework [29], automatic monitoring addresses both the content of the service and the delivery. It involves the introduction of more meaningful monitoring indicators (relative and comparative measures) and user customisable control of alert delivery.

\section{Investing process management}

The contemporary portfolio management paradigm focuses on how to define an optimal portfolio allocation matching investor needs. The financial discipline does not cover the 
ongoing management of investing operations. The purpose of investing process management is to facilitate the systematic management of the whole investing process from planning to control.

\section{Evaluation results}

The relevance evaluation (EVAL 1) served as a means to exclude irrelevant initiatives and to explore the importance of problem-solving of initiatives. The evaluation of design approach required (EVAL 2) was not a formative evaluation, but a technical evaluation to filter out routine design and platform-specific tasks. For new solutions, which needed further conceptualisation, the acceptance evaluation (EVAL 3) was the defining step to assess their utility from the investor point of view.

\section{Functional and design issues}

The most uniform evaluation opinions regarding functional issues were related to performance feedback and information overflow. All investor personas found improvements in these matters essential. Regarding the discovered excess platform complexity, there was no clear correlation between evaluation feedback and investing personas. It was more a question of engagement with the platform: if an investor's main use of a platform was only to execute transactions, complexity did not manifest. Behavioural provocation - attempts to urge investors to make more transactions were noticed, except for traditionalist and passive investor personas. However, all investors in the sample claimed to be immune to behavioural influence due to their experience. Reducing behavioural implications of the user interface was considered useful, but with no expected impact on investing outcome and performance.

\section{New decision support solutions}

The holistic profiling utility was presented as a necessary support utility for other initiatives. In the anticipation of improved functionality, investors found the usefulness of this support function obvious. Having the possibility of a hierarchical portfolio structure was important across investor personas. However, the interest was limited to consolidating multiple portfolios - dividing portfolios to subaccounts was ignored. Intelligent investment selection was considered useful by all personas, but especially important for stock-pickers and the active-passive investor persona. The Interactive portfolio revisioning initiative was considered intriguing by all investing personas. Even a professional asset manager consulted wanted to have access to such a tool to demonstrate the behaviour of alternative portfolios using scenario simulations. Evaluation results of automatic monitoring function did not depend on investing style, but whether an investor was interested in following portfolio developments.

The concept of investing process support was not found to be relevant except by the two investors of the active-passive engaged investor persona. They had already created their own spreadsheets to stay systematic. For other investors, the initiative remained an abstract concept and the benefits for them were difficult to formulate. 


\section{Discussion}

\section{Lessons learned from investor evaluations}

The investor persona-based analysis arrangement aimed to recognise the fact that an artifact's performance is related to the environment in which it operates [19]. The defined personas relate to an investing style, but not an investor mindset. Beyond investor personas, matters like interaction frequency [30], intellectual motives, beliefs, and time available seemed to affect a service perception in addition to investing personas.

The results of evaluations imply that investors' investing behaviour can be positively or negatively affected by the platforms in use. Investors to a certain extent neglect investing planning and portfolio level management [17]. The positive reaction to investor profiling and interactive portfolio revisioning supports the notion that investors are ready to change their behaviour if these activities are supported with appropriate tools. Due to this nudging effect towards more normative investing practices, investing performance can be expected to improve not only due to better decision support, but investing practices may also improve.

The role of sociopsychological perceptions complementing utilitarian (read: financial) needs [31] can be seen in the high perceived relevance of features that are intellectually intriguing or enjoyable. Simulation of portfolios with historical or future scenario data serves as an example of such a function. Even if considered useful and usable, functions may not be put into service due to other issues, such as the 'bundled services' problem - an investor commented: "I would never use it as then I would be stuck with that one platform".

Despite complaints about user-friendliness and usability, investors did not consider losing time due to these issues. Investors provided anecdotes of getting used to coping with counterintuitive user interfaces and learning some 'tricks' on how to overcome obstacles. This adaptability was exhibited in comments where first, an investor finds a function problematic, not intuitive to use, or unfit for purpose but then explains that "..., but it doesn't bother me any more", ".., but I can manage with it" or "It maybe takes me one or two months to learn a platform".

The investor evaluation results confirm the need for control and interactivity in service system design [32], but contradict claims like "many investors seek large amounts of data, e.g. real-time stock quotes". Actually, the last phrase contradicts itself: real-time quotes are not essential for true investors with their long investing horizon.

\section{Mismatches between investor needs and service offerings}

Interestingly enough, a need for partial 'de-digitalisation' was noticed. In addition to online services, several investors wished for optional access to human advisors. Advice was requested for analysis of the current investing environment and for special investing issues. This is not a question about an alternative channel to provide a service, but a complementary service. A mixture of self-service and human advice would help service providers in customer retention [33] while facing considerable investor demand for such a hybrid service [34].

The majority of investors in the study had suspicions of conflict of interest with online investing platform providers. This manifested in investors feeling a push to make more transactions. There were also doubts on the reasons for difficulties to find fee reports and 
long-term performance reports. Additionally, the introduction of 'inactivity fees' for investors is hard evidence for a conflict of interest and testimony for a need for new business models.

Automated investing service providers have managed to introduce a new digital business model, where investors are charged for a percentage of their wealth, instead of transactions made. While this may be a desirable solution for 'hands-off' investors it was not considered acceptable by the self-directed investors of the investor sample; they wanted to make the investing decisions by themselves. However, as this example shows, customer segment specific new business models can be introduced.

As costs of security transactions and financial assets custody approach zero, value creation leading to increased profits for online platform providers faces challenges. The main priority and activity of high perceived value for many investors is finding 'winning investments'. Although "information has suffered inflation" as a professional asset manager remarked, a proportion of investors were still willing to pay for high-quality third-party information and analyses. Specialised human advice was also valued by the investors struggling with information overflow. Due to their central role, platform providers have a unique position to offer a bundle of integrated services adding more value to their customers. They are also the only operator in possession of all investor portfolio and transaction information. Creating value by using this 'investor big data' is currently not exploited.

Based on the multiple investor evaluations done, the value of in-house services provided can be improved by removing the shortcomings in current information systems and introducing differentiating and adoptable new decision support functions. From a value creation point of view, online services for self-directed investors will always face a challenge: true value lies in optimal investing decisions made by the investor; targeted value accumulation can take years to accomplish.

\section{Service architecture and modularisation}

A proportion of investors participating in this study used several online platforms due to their specific strengths in certain services like financial research, monitoring, providing real-time prices, and profiled news. This is an indication of a need to create an investing toolbox from components. It is unlikely that one single investing platform would become an all-out service provider, being best in class in all services for all customers. Parallel use of overlapping platform services implies a need for modularisation. A more networked investing service sector with interchangeable components would allow specialisation and economies of scale, and would reduce the need for overlapping and redundant system development.

Investing system components can be implemented by third parties and linked to an investing platform in different ways. Required links can be divided into independent, interfaced, and integrated. Independent components do not need data exchange with other modules. Interfaced components need at least an 'at-will' interface to portfolio, performance, investing account, and transaction data. Use of services in the interfaced group is not continuous, but takes place occasionally, thus not necessarily requiring a close real-time integration. Components labelled integrated require continuous access to investment data and perform best with a real-time application programming interface or as an embedded part of an investing platform. 


\section{Lessons learned on design science master plan process}

Most seminal design science literature emphasised a problem or problems as the starting point of a research process [35-38]. This study raised opportunities as an equivalent motivation for development. From a service science perspective, just solving obvious problems would not end up in modularisation and service redesign. For the type of research with multiple issues to address, a design science master plan project is considered a crucial step which has to precede more focused and traditional design science projects.

In practice, the research tasks depicted in Figure 2-1 cannot proceed in a strictly sequential manner. In particular, the analyses and solution concept development proceeded in a more continuous and parallel way. In the studied context of platforms, it proved also essential to acknowledge the multiple customer segments and subsegments therein (personas) - to avoid conflicting results from a heterogenic group of users [15]. Investor personas see the value of individual services differently.

\section{Conclusions}

A design science master plan process was developed to find the most impactful set of solutions among the many initiatives. The results of the research process revealed that investors are ready to accept a broader range of decision support if they do not have to change their investing processes currently in use. Investors can, in any case, be nudged to apply lessons from empirical research, assuming that they do not have to adopt 'black-box' solutions. Self-directed investors prefer to maintain the feel of control through interactive decision-making. Investors suffer from unfiltered information overflow with insufficient analytics and interpretation. In this context, online platform services add negative value by attempting to maximise the amount of information and alerts provided. Improvements in user experience would provide immediate emotional value. Beyond online platform functionality, signs of general mismatch between online platforms services and investor needs emerged. Investors also sensed conflicts of interest - being persuaded to make unnecessary transactions to add to service provider profits.

The service life-cycle concept helps to understand the gap between user needs and services provided. Many incumbent online platforms have their origins rooted in digitalisation of broker services for traders. The resulting development priorities can be portrayed with an investor comment: "Has anybody ever asked investors what the platforms should do?" In the past, making inexpensive online transactions created value as such, and a profit model based on transaction commissions was rational. Later, investors joined the clientele with partially diverging value perception. Nevertheless, the business logic remained the same. The gap between the transaction-oriented profit model and investor customers has widened due to increasingly popular passive investing and exchange traded funds. At the same time, platform providers face the pressure of competition from commission-free services. Service differentiation is no longer possible with lower costs; new sources for value creation have entered the picture.

At the current point in time, platforms are offered for a heterogeneous group of traders and investors. Further still, the self-directed investor segment includes multiple subsegments from passive portfolio investors to active stock-pickers. Considering the needs of multiple customer segments, an incremental change in efficiency and quality of services [39] does not provide a solution, as change should proceed in multiple directions. Service modularisation is a potential solution in this context of similar proprietary functions existing on available 
platforms. In addition to proprietary solutions, online trading platforms could provide third party services for matching customer segments - instead of trying to be all things for all users.

Regarding incumbent investing service modularisation, future work is needed to address the issues of new business models, security concerns, privacy issues, and financial policy. Incumbent service providers are seen as reluctant to share their investor data with external services. Policy measures beyond open banking directives may be needed to cultivate flexible architecture [40] to unlock the full potential of the service provider ecosystem.

\section{References}

1. T. Odean, Do investors trade too much?, American economic review, 89(5) 12791298, (1999).

2. B. M. Barber and T. Odean, Trading is hazardous to your wealth, The Journal of Finance, 55(2) 773-806, (2000).

3. M. Grinblatt and M. Keloharju, The investment behavior and performance of various investor types, Journal of financial economics, 55(1) 43-67, (2000).

4. A. Kamesaka, J. R. Nofsinger, and H. Kawakita, Investment patterns and performance in Japan, Pac-basin financ j, 11(1) 1-22, (2003).

5. P.-G. Shu, S.-B. Chiu, H.-C. Chen, and Y.-H. Yeh, Does trading improve individual investor performance?, Rev quant fin and acc, 22(3) 199-217, (2004).

6. A. Anderson, All guts, no glory: Trading and diversification among online investors, European Financial Management, 13(3) 448-471, (2007).

7. N. Y. Oh, J. T. Parwada, and T. S. Walter, Investors' trading behavior and performance: Online versus non-online equity trading in Korea, Pacific-Basin Finance Journal, 16(1-2) 26-43, (2008).

8. B. M. Barber, X. Huang, T. Odean, and C. Schwarz, Attention induced trading and returns: Evidence from Robinhood users, Journal of Finance, forthcoming (2021).

9. G. W. Eaton, T. C. Green, B. Roseman, and Y. Wu, Zero-commission individual investors, high frequency traders, and stock market quality, High Frequency Traders, and Stock Market Quality(2021).

10. I. Welch, The Wisdom of the Robinhood crowd, NBER, (2020).

11. A. Kalda, B. Loos, A. Previtero, and A. Hackethal, Smart (Phone) Investing? A within Investor-time Analysis of New Technologies, NBER, (2021).

12. C. Fink, Why millennials gravitate to new brands in online investing, Journal of Brand Strategy, 9(4) 401-407, (2021).

13. R. G. Ibbotson and P. D. Kaplan, Does asset allocation policy explain 40, 90, or 100 percent of performance?, Financial Analysts Journal, 56(1) 26-33, (2000).

14. B. M. Barber and T. Odean, The behavior of individual investors, in Handbook of the Economics of Finance, 2, Elsevier, 2013, 1533-1570.

15. C. M. Jones, D. Shi, X. Zhang, and X. Zhang, Understanding Retail Investors: Evidence from China, Working paper, Columbia Business School, NY(2021).

16. B. M. Barber and T. Odean, Does Online Trading Change Investor Behavior?, European Business Organization Law Review, 3(1) 83-128, (2002).

17. A. Paatela and J. Weiss, Behavioral Analysis of Sustained Individual Investors, European Journal of Economics and Business Studies, 7(2) 54-66, (2021).

18. A. R. Hevner, S. T. March, J. Park, and S. Ram, Design science in information systems research, MIS quarterly, 28(1) 75-105, (2004). 
19. S. T. March and G. F. Smith, Design and natural science research on information technology, Decision support systems, 15(4) 251-266, (1995).

20. J. F. Nunamaker Jr, M. Chen, and T. D. Purdin, Systems development in information systems research, Journal of management information systems, 7(3) 89-106, (1990).

21. S. Gregor and D. Jones, The anatomy of a design theory, 8(5) 312-335, (2007).

22. M. L. Markus, A. Majchrzak, and L. Gasser, A design theory for systems that support emergent knowledge processes, MIS quarterly, 26(3) 179-212, (2002).

23. J. G. Walls, G. R. Widmeyer, and O. A. El Sawy, Building an information system design theory for vigilant EIS, Information systems research, 3(1) 36-59, (1992).

24. J. G. Walls, G. R. Widermeyer, and O. A. El Sawy, Assessing information system design theory in perspective, JITTA, 6(2) 43-58, (2004).

25. C. Sonnenberg and J. Brocke, Evaluations in the science of the artificialreconsidering the build-evaluate pattern, DESRIST, (2012).

26. J. Holmström, M. Ketokivi, and A.-P. Hameri, Bridging practice and theory: A design science approach, Decision Sciences, 40(1) 65-87, (2009).

27. W. F. Sharpe, Integrated asset allocation, Finance analysts j, 43(5) 25-32, (1987).

28. B. M. Barber, X. Huang, T. Odean, and C. Schwarz, Attention induced trading and returns: Evidence from Robinhood users, SSRN 3715077, (2020).

29. C.-W. Tan, I. Benbasat, and R. T. Cenfetelli, IT-mediated customer service content and delivery in electronic governments: An empirical investigation of the antecedents of service quality, MIS quarterly, 37(1) 77-109, (2013).

30. M. J. Bitner, B. H. Booms, and M. S. Tetreault, The service encounter: diagnosing favorable and unfavorable incidents, Journal of marketing, 54(1) 71-84, (1990).

31. R. G. Qiu, Service science: The foundations of service engineering and management. John Wiley \& Sons, 2014.

32. D. Xin Ding, P. J.-H. Hu, R. Verma, and D. G. Wardell, The impact of service system design and flow experience services, J. Serv. Res., 13(1) 96-110, (2010).

33. A. Scherer, N. V. Wünderlich, and F. Von Wangenheim, The Value of Self-Service, MIS quarterly, 39(1) 177-200, (2015).

34. T. Cocca, Potential and limitations of virtual advice in wealth management, Journal of Financial Transformation, 44(1) 45-57, (2016).

35. K. Peffers, T. Tuunanen, M. A. Rothenberger, and S. Chatterjee, A design science research methodology for information systems research, Journal of management information systems, 24(3) 45-77, (2007).

36. H. Takeda, P. Veerkamp, and H. Yoshikawa, Modeling design process, AI magazine, 11(4) 37-37, (1990).

37. B. Kuechler and V. Vaishnavi, On theory development in design science research: anatomy of a research project, Eur j inform syst, 17(5) 489-504, (2008).

38. P. Offermann, O. Levina, M. Schönherr, and U. Bub, Outline of a design science research process, in Proceedings of the 4th International Conference on Design Science Research in Information Systems and Technology, (2009).

39. R. Barras, Towards a theory of innovation in services, Research policy, 15(4) 161173, (1986).

40. M. Grisot, O. Hanseth, and A. A. Thorseng, Innovation of, in, on infrastructures, Journal of the Association for Information Systems, 15(4) 2, (2014). 